\title{
Aprendizagem significativa no contexto do ensino remoto
}

\author{
Significant learning in the contexto of remote teaching
}

Jucélia Cruz

Mestre em Práticas Docentes no Ensino Fundamental pela Universidade Metropolitana de Santos (2018).

Possui graduação em Pedagogia (2013) e Letras - Português e Inglês (2003).

Atualmente é Assistente de Direção na Secretaria Municipal de Educação de Santos.

Universidade Metropolitana de Santos - UNIMES celiajuz@gmail.com

\begin{abstract}
Elisabeth dos Santos Tavares Doutorado em Educação (Currículo) (2009) Mestrado em Educação (Currículo) (2003) ambos pela Pontifícia Universidade Católica de São Paulo e graduação em Licenciatura em Pedagogia pela Universidade Metropolitana de Santos (1975). Atuação na Educação Básica Pública como professora, diretora de escola, supervisora de ensino e delegada de ensino de Santos. Atualmente é professora no Programa de Mestrado Profissional Práticas Docentes no Ensino Fundamental da Universidade Metropolitana de Santos, atuando principalmente nos temas: Política Educacional, Formação de Professores, Tecnologia e educação. Universidade Metropolitana de Santos - UNIMES elisabeth.tavares@unimes.br

Michel da Costa

Doutorado em Educação Matemática (2019) pela Universidade Anhanguera de São Paulo e Mestrado em Educação Matemática (2010) pela Universidade Bandeirante de São Paulo, Pós Graduação - Especialização em Educação a Distância pela Universidade Metropolitana de Santos - UNIMES (2018), Graduação em Ciências - Habilitação Plena em Matemática (2000), Graduação em Pedagogia (2003) com experiência na área do ensino, com ênfase em Educação Matemática, atuando nos seguintes temas: formação de professores, letramento estatístico, educação, educação matemática, tecnologias e currículo. Atualmente, é Professor da Universidade Metropolitana de Santos - UNIMES e Supervisor de Ensino efetivo na Prefeitura Municipal de Cubatão. michel.costa@unimes.br
\end{abstract}

Resumo: O presente artigo registra parte de uma pesquisa de um mestrado profissional intitulada "As tecnologias de comunicação e informação como fator motivacional para o ensino fundamental”. Os estudos foram, em seguida, ampliados acerca da aprendizagem significativa considerando o contexto do ensino remoto com a adoção da suspensão das aulas presenciais em virtude da pandemia de COVID-19. Apresentase uma descrição do que vem a ser essa aprendizagem, em que condições ela pode ocorrer e as formulações iniciais sobre o tema a partir da visão de estudiosos como Ausubel e seus colaboradores e possibilidades de ensino e aprendizagem com uso de TIC - Tecnologias de Informação e Comunicação para o processo educativo. Tais formulações e estudos propiciam uma reflexão quanto às possibilidades desses recursos como facilitadoras na construção do conhecimento pelo aluno do Ensino Fundamental de forma significativa e crítica. A pesquisa desvelou desigualdades sociais dos educandos de uma instituição pública de ensino e lacunas na formação docente no uso de recursos tecnológicos.

Palavras-chave: Tecnologia Digital de Informação e Comunicação. Aprendizagem significativa. Ensino Remoto. 


\begin{abstract}
This paper registers part of a professional Master's research entitled "Communication and information technologies as a motivational factor for elementary education". The studies were then expanded on meaningful learning considering the context of remote education with the adoption of the suspension of face-to-face classes due to the pandemic of COVID-19. It presents a description of what this learning is, in what conditions it can occur and the initial formulations on the theme from the perspective of scholars like Ausubel and his collaborators and possibilities of teaching and learning using ICT Information and Communication Technology for the educational process. Such formulations and studies provide a reflection on the possibilities of these resources as facilitators in the construction of knowledge by the elementary school student in a significant and critical way. The research unveiled social inequalities of students in a public educational institution and gaps in teacher training in the use of technological resources.
\end{abstract}

Keywords: Information and Communication Technology. Meaningful learning. Remote Teaching.

\title{
1 Introdução
}

Dar sentido a algo, ter motivo para algo é atribuir-lhe importância, legitimidade, utilidade. Para que se atribuam tais características a esse algo, é necessário que haja a diversidade que propicia a utilização de algumas competências como a compreensão do processo em suas etapas de realização, a percepção da contribuição para a sociedade e para a própria autonomia, liberdade e independência dos sujeitos. Também, não esquecendo, das intervenções acerca da produção apresentada para que se possa ajustá-la, melhorando a sua qualidade.

Todos os atributos citados como características para dar sentido a algo nos remete ao que chamamos de aprendizagem significativa. Uma aprendizagem em que o aluno atribui um valor, um significado ao conteúdo aprendido.

Vale dizer, que o processo de ensino e de aprendizagem é uma construção de significados, caracterizado como uma troca entre professor e estudante, cujo efeito pressupõe a iniciação do aluno em um determinado conhecimento. Ensinar e aprender são, basicamente, compartilhamento de significados, diálogo. Essa ideia é desenvolvida com base na visão humanista de Novak (1981) para quem a experiência de ensinar e aprender pressupõe troca de significados e sentimentos, portanto, o desejo de aprender, a afetividade.

Tais significados são construídos aos poucos e progressivamente compartilhados entre professor e aluno. O professor tem em mente os significados que deseja compartilhar com o aluno e planeja a partir destes significados o que espera que o aluno aprenda. Já o aluno não sabe que significados mobilizaram o professor para a condução do processo e ele é conduzido a construir sentidos e significados que se aproximem dos propostos para o ensinar daquele conteúdo.

A metodologia foi de abordagem qualitativa de cunho descritivo e interpretativo, sendo feita por estudos bibliográficos, documentais e posteriormente pesquisa em uma Unidade Escolar, 
sendo essa escolhida por encontrar-se na área de maior vulnerabilidade social de um município da Região Metropolitana da Baixada Santista, a qual os profissionais da educação aceitaram participar da investigação para fins acadêmicos e científicos, atendendo aos princípios éticos e formais, sendo um recorte de uma dissertação de mestrado, sendo ampliada a investigação ao considerar o contexto do isolamento social, consequência da pandemia de COVID 19.

Nesse compartilhamento do conhecimento, torna-se imprescindível o desejo do aluno em estar na escola e fazendo o que se propõe. O que, possivelmente, se dá quando ele e o professor percebem o real valor da educação e do que fazem, considerando o currículo como instrumento com a potencialidade de estruturar as ações desenvolvidas pelas instituições de ensino, as vivências proporcionadas pelos processos de ensino e de aprendizagem e as práticas pedagógicas, seu planejamento e intencionalidade de forma crítica e reflexiva, tal como indicam Sacristán; Perez (1998) e Saviani (1986).

\section{Aprendizagem Significativa na visão de Ausubel}

As formulações iniciais acerca da aprendizagem significativa de Ausubel são da década 60. A insatisfação de David Ausubel vivida em sua escolarização pela falta de condições que contribuíssem para seu próprio desenvolvimento e propiciassem uma aprendizagem reflexiva e significativa deu origem a Teoria da Aprendizagem Significativa. Como psiquiatra e psicólogo do desenvolvimento dava voz ao outro em sua singularidade e individualidade. Essa trajetória pessoal e profissional de Ausubel contribuiu para definir as linhas centrais da sua teoria: fazer da escola o local para uso da capacidade de compreender e atribuir significados, focalizar a relevância do processo relacional na aquisição de conhecimentos. Uma proposta psicoeducativa que busca explicar a aprendizagem escolar e o ensino em uma perspectiva cognitiva e, atualmente, em uma visão crítica.

A Aprendizagem Significativa de Ausubel é uma teoria cognitivista e construtivista sobre o processo de aquisição do conhecimento. Como teoria cognitivista descreve o que sucede quando o ser humano organiza e atribui significados à realidade em que se encontra - significados em constante transformação. Já como teoria construtivista interpreta a aquisição do conhecimento na asserção de que ver, ouvir, cheirar, apalpar, compreender, elaborar, relacionar, transformar e lembrar são atos de construção do sujeito, atos que dependendo das circunstâncias e condições pessoais fazem maior ou menor uso dos estímulos externos e da relação com o outro. 
Marco Antônio Moreira questiona "O que é afinal aprendizagem significativa”? E tomando este questionamento, apresenta uma descrição do que vem a ser essa aprendizagem e em que condições ela pode ocorrer.

A aprendizagem significativa de Ausubel é uma aprendizagem por compreensão: [...] caracteriza-se pela interação entre o novo conhecimento e o conhecimento prévio. [...] o novo conhecimento adquire significados para o aprendiz e o conhecimento prévio fica mais rico, mais diferenciado, mais elaborado em termos de significados e adquire mais estabilidade (MOREIRA, 2005, p.13).

A Teoria da Aprendizagem Significativa é concebida como processo de compreensão, reflexão e atribuição de significados do sujeito, em interação com o meio social, a cultura e por ela ser constituído. Essa concepção de aprendizagem significativa diz respeito à integração de novas informações em um complexo processo pelo qual aquele que aprende adquire conhecimento. Este processo relacional implica a concepção de complexidade de Morin (2007), que diz respeito ao tecido dos acontecimentos, ações, interações, retroações, determinações e acasos constituintes do contexto social, no qual está o ser que aprende.

Segundo La Taille (1992), representante piagetiano, as relações de coerção embotam o desenvolvimento e compreensão. Só as relações sociais de livre intercâmbio de pontos de vista permitem a autonomia e a possibilidade a crianças e adultos de se emanciparem intelectual, moral e afetivamente.

A aprendizagem significativa de Ausubel é uma aprendizagem por compreensão. Para a ocorrência da aprendizagem significativa são necessárias algumas condições:

1. Partir do que o aprendiz conhece - cognições já adquiridas e construídas pelo aprendiz;

2. Organizar o material a partir de conceitos mais amplos para os mais específicos;

3. Utilizar linguagem que propicie a comunicação com o aprendiz;

4. Utilizar recursos facilitadores da aprendizagem significativa: substantiva e programaticamente e os princípios da diferenciação progressiva e reconciliação integrativa;

5. Fazer uso de organizadores para superar o limite entre o que o aluno já sabe e o que ele precisa saber;

6. Interagir do professor e aprendiz com autonomia no processo de aprendizagem no meio social e cultural;

7. Considerar as inter-relações e análise dos recursos humanos e materiais que propiciam ao aluno possibilidade de compreender e refletir sobre o impede que isso ocorra e que comprometem o processo de aprendizagem. 
Com o uso da capacidade de compreender ocorrerá a aprendizagem por reflexão ou por solução de problemas. É um processo mais complexo que o da aprendizagem por compreensão, segundo Ausubel e Robinson (1969), envolve um hiato entre o conhecimento que o estudante dispõe e o que tem que alcançar para a solução do problema.

O encaminhamento dos dados e da solução é realizado pela retomada ou transformação e aplicação direta do conhecimento reorganizado a partir do padrão de regras, constituindo uma solução por repetição. Como na aprendizagem significativa por compreensão, a aprendizagem por reflexão também, requer ao aprendiz que reconheça que o problema existe e tenha significado para ele; tenha disposição para querer solucionar o problema; domine os conceitos com os quais irá trabalhar para a solução do problema; analise se entendeu a natureza do problema e se possui material necessário para trabalhá-lo.

Dessa forma, requer quanto ao professor que tenha realizado uma Aprendizagem Significativa e propiciado aos alunos o domínio dos conceitos com os quais trabalharão para a solução do problema, tenha realizado avaliações sobre a aprendizagem conceitual dos alunos; tenha levado o aprendiz a reavaliar os passos dados para a solução do problema e localizar seus erros e tenha oferecido exercícios que desafiem o aprendiz em termos de um obstáculo a ser removido, porém sem frustrá-lo.

As pessoas têm uma organização cognitiva interna baseada em conhecimentos de caráter conceitual, sendo que a sua complexidade depende, das relações que os conceitos estabelecem entre si. Essas relações têm caráter hierárquico, de maneira que a estrutura cognitiva é compreendida como uma rede de conceitos organizados de modo hierárquico de acordo com o grau de abstração e de generalização.

Nesse contexto, a aprendizagem significativa é um processo por meio do qual um novo conhecimento se relaciona de maneira lógica à estrutura cognitiva do estudante, incorporado a essa estrutura como a essência do novo conhecimento.

Assim, são componentes que caracterizam o processo da aprendizagem significativa:

1 Conceito inclusor ou subsunçor - são os conceitos ou ideias que existem previamente na estrutura cognitiva, servindo de ponto de localização para as novas ideias que são os objetos da aprendizagem.

2 Inclusão obliteradora - é o processo de interação entre o material de aprendizagem e os conceitos inclusores. Tanto o conceito inclusor como o novo material ficam modificados.

3 Assimilação - os resultados dos processos de inclusão obliteradora é uma autêntica assimilação 
SOARES, Tárcila Lorrane Fernandes de Souza; SANTANA; Ícaro Silva de; COMPER, Maria Luiza Caires. Ensino remoto na pandemia de COVID-19: lições aprendidas em um projeto de extensão universitário

entre os significados anteriores e os novos, o que implica uma estrutura mais rica e diferenciada que a original.

\section{Contributos e formulações para o desenvolvimento da aprendizagem significativa}

Para o desenvolvimento da Teoria da Aprendizagem Significativa de Ausubel conta-se com dois grandes colaboradores. Um deles foi Joseph Novak, biólogo de formação, que desde cedo começou por se dedicar ao tema da educação científica. A proposta de Novak é mais ampla e ambiciosa do que a de Ausubel, já que defende uma Teoria da Educação que integra a Teoria da Aprendizagem Significativa.

A teoria de Novak assenta na ideia de que a educação é um conjunto de experiências cognitivas, afetivas e psicomotoras que, quando guiadas pela Teoria da Aprendizagem Significativa, conduzirão ao engrandecimento (empowerment) do educando, preparando-o para lidar com um mundo em mudança. Ele introduziu os chamados "mapas conceptuais" ou mapas de conceitos em meados da década de setenta, juntamente, com seus colaboradores na Universidade de Cornell, nos Estados Unidos.

Vale destacar que a teoria de Ausubel ao tratar da aprendizagem cognitiva, baseia-se na premissa de que existe uma estrutura em constante mutação. Essa estrutura cognitiva é entendida como o conteúdo total de ideias de um certo indivíduo e a forma como estão organizadas. Para ele, a aprendizagem é organização e integração de informações na estrutura cognitiva. O armazenamento de informações pelo cérebro é altamente organizado, formando uma hierarquia conceitual.

A aprendizagem significativa apresenta-se em três tipos:

1 Subordinada, derivada $\mathrm{O}$ conhecimento novo subordina-se aos pré-existentes mais gerais e abrangentes. O novo material é assimilado como um exemplo específico de um conceito previamente estabelecido na mente do sujeito.

2 Supra ordenada, subordinante em que o conhecimento prévio é mais específico que o novo material.

3 Combinatória, correlativa em que o conhecimento novo relaciona-se com os subsunçores (facilitadores) existentes sem os subordinar e sem ser por eles subordinados. 
Além de todas as estratégias e instrumentos facilitadores da aprendizagem significativa deve-se mencionar dois instrumentos muito frequentemente associados a essa aprendizagem que são os mapas conceituais e o diagrama de Gowin.

Mapas conceituais são diagramas indicando relações entre conceitos, ou entre palavras que usamos para representar conceitos. Os mapas são propostos como uma estratégia potencialmente facilitadora de uma aprendizagem significativa. Eles, segundo Moreira, podem ser importantes mecanismos para focalizar a atenção do planejador entre o conteúdo que se espera que seja aprendido e aquele que serve de veículo para a aprendizagem.

O conteúdo curricular está contido em fontes de conhecimento tais como artigos de pesquisa, ensaios, poemas, livros. Mapas conceituais podem ser úteis na análise desses documentos a fim de se tornar adequado para instrução do conhecimento neles contido. Eles foram desenvolvidos para promover a aprendizagem significativa.

A análise do currículo e o ensino sob uma abordagem ausubeliana, em termos de significados, implicam: identificar a estrutura de significados aceita no contexto da matéria de ensino; identificar os subsunçores, servindo de ponto de localização para as novas ideias que são os objetos da aprendizagem necessários para a aprendizagem significativa de outros conhecimentos; identificar os significados preexistentes na estrutura cognitiva do aluno; organizar sequencialmente o conteúdo e selecionar materiais curriculares, usando as ideias de diferenciação progressiva e reconciliação integrativa como princípios programáticos e ensinar usando organizadores prévios (pré-requisitos), para fazer pontes entre os significados que o aluno já tem e os que ele precisaria ter para aprender significativamente a matéria de ensino, bem como para o estabelecimento de relações explícitas entre o novo conhecimento e aquele já existente e adequado para dar significados aos novos materiais de aprendizagem.

Outro contributo para o desenvolvimento da Teoria da Aprendizagem nos trouxe Dixie Bob Gowin, tal como Novak. No seu trabalho de doutoramento, em Filosofia da Ciência, empenhou-se em compreender a estrutura e o processo de criação do conhecimento científico.

Tendo-se apercebido de que os alunos de ciências saíam dos laboratórios com pouca ou nenhuma consciência do que tinham estado a fazer seguindo protocolos experimentais tipo receita, e sem terem aprendido significativamente aquilo que se pretendia que aprendessem, Gowin começou por desenvolver o chamado método das 5 perguntas, que se destina também a “desempacotar" o conhecimento apresentado, por exemplo, num artigo científico ou num capítulo de um livro.

As perguntas apontam para se saber: 
1 Qual é a questão determinante do trabalho?

2 Quais são os conceitos-chave?

3 Quais são os métodos que foram utilizados para responder à questão-chave?

4 Quais são os principais juízos cognitivos no trabalho?

5 Que juízos de valor foram feitos no trabalho?

Para Gowin a aprendizagem, enquanto processo de pesquisa individual e idiossincrática, distingue-se do ensino, um ato social, e deverá ser encarada como uma estrutura em que a interação entre os acontecimentos, os conceitos e os fatos desempenham um papel decisivo. No processo de ensino e de aprendizagem, o professor e o aluno estão, pois, intimamente envolvidos num compartilhar de significados a respeito dos conhecimentos veiculados pelo material educativo.

Na sequência do método das cinco perguntas, Gowin criou um dos importantes artefatos da Teoria da Aprendizagem Significativa, o "V do conhecimento", também conhecido como "V epistemológico", "V heurístico" ou "V de Gowin". Trata-se de um instrumento que se enquadra perfeitamente no paradigma construtivista atual, e que, quando convenientemente usado, pode contribuir de modo decisivo para facilitar a aprendizagem significativa da ciência.

É um instrumento criado para auxiliar a resolver um problema ou para entender a estrutura e os processos que teremos que utilizar para construir o conhecimento. Este instrumento, como o seu nome indica, assume a forma de um "V". (Moreira, 2006)

$\checkmark$ No centro do V irá redigida a pergunta central que queremos ver respondida ao longo da nossa investigação.

$\checkmark$ No vértice do $V$ situam-se os dados e os acontecimentos.

$\checkmark$ No lado direito do $\mathrm{V}$ iremos registar as observações feitas, realizar afirmações sobre conhecimentos, registar as transformações produzidas e fazer referências a juízos de valor relacionados com o problema em estudo.

$\checkmark$ No lado esquerdo do V colocaremos todos os aspectos teóricos e conceituais sobre o problema em estudo. 
Figura 1 - Teoria da Aprendizagem Significativa - V do Conhecimento

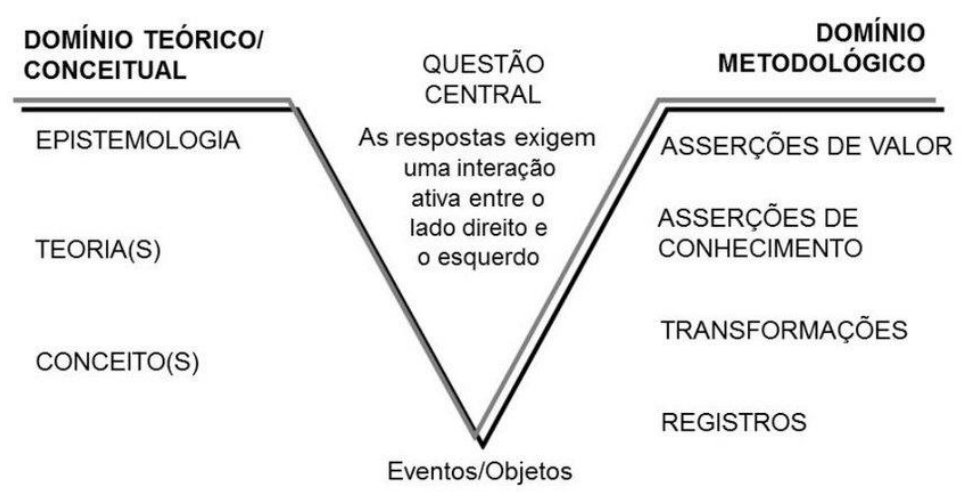

Fonte: https://www.researchgate.net/figure/Figura-1-Estruturacao-do-V-de-Gowin fig1 332770917 Acesso em: 31 maio 2020.

Tais contribuições, na forma de mapas ou diagramas, usados com a orientação do professor, envolve o aluno numa teia construtivista em que concepções e metodologias, reflexão e ação, interagem dialeticamente construindo- se uma aprendizagem significativa. Essa aprendizagem significativa caracteriza-se pela interação entre o novo conhecimento e o conhecimento prévio. Nesse processo, que é não literal e não arbitrário, o novo conhecimento adquire significados para o aprendiz e o conhecimento prévio fica mais rico, mais diferenciado, mais elaborado em termos de significados, e adquire mais estabilidade (Moreira, 1999, 2000).

Seria pertinente dizer que se aprende a partir daquilo que já se conhece. Em 1963, Ausubel já nos chamava atenção para isso. Atualmente, já se reconhece que a mente é conservadora, aprende-se a partir daquilo existe na estrutura cognitiva.

O aluno não é um receptor passivo na aprendizagem significativa. $\mathrm{Na}$ verdade, ele deve fazer uso dos significados que já internalizou, de maneira substantiva e não arbitrária, para poder captar os significados dos materiais educativos. Nessa construção, ele produz seu conhecimento.

Para David Ausubel, no processo de ensino importa que a aprendizagem seja significativa, isto é, que o material a ser aprendido faça "sentido" para o aluno. Vale ressaltar ainda que mesmo que o material a ser aprendido seja significativo, é necessário que o aluno queira aprender.

Corti e Vóvio (2007) defendem que:

A disposição para aprender é outro elemento importante na aprendizagem. Trata-se da maneira pela qual a pessoa se vê no processo de aprendizagem, percebe o que vai aprender e como se sente diante desse desafio. A disposição também é construída nas experiências vividas, tanto pode ser consequência de uma necessidade, um interesse ou desejo pessoal, como de uma motivação ou estímulo vindo de outras pessoas. (CORTI; VÓVIO, 2007 apud MERAZZI; OAIGEN, 2008, p.18-19). 
Nessa perspectiva, o "que faça sentido" passa pela provocação capaz de acionar o aluno a querer aprender e pelo valor que ele atribui ao novo conhecimento. Sendo assim, é fundamental que o aluno tenha como relevante o estudo para si. Como afirmam Postman e Weingartner (1969) relevância aquela que permitirá ao sujeito fazer parte de sua cultura e, ao mesmo tempo, estar fora dela, manejando-a de maneira crítica, mudar sem ser dominado pela mudança, numa aprendizagem significativa subversiva, ou crítica.

\section{Ensino Remoto em virtude da COVID-19}

Em dezembro de 2019, foi confirmada em Wuhan, na China, o primeiro caso de uma doença sindrômica, causando entre outros agravamentos uma forte pneumonia e problemas respiratórios. Os estudos diagnosticaram que se tratava de um novo coronavírus, uma família de vírus bastante presente entre alguns animais e que raramente infectam pessoas.

A COVID-19 é uma doença causada pelo coronavírus, denominado SARS-CoV-2, que
apresenta um espectro clínico variando de infecções assintomáticas a quadros graves. De
acordo com a Organização Mundial de Saúde, a maioria (cerca de $80 \%$ dos pacientes
com COVID-19 podem ser assintomáticos ou oligos sintomáticos (poucos sintomas), e
aproximadamente $20 \%$ dos casos detectados requer atendimento hospitalar por
apresentarem dificuldade respiratória, dos quais aproximadamente $5 \%$ podem necessitar
de suporte ventilatório. (BRASIL, 2020, s/p)

Desde o final para o início do ano de 2020, o surto foi categorizado como Emergência de Saúde Pública de importância internacional em 30 de janeiro de 2020, onde a Organização Mundial de Saúde - OMS, declarou em 11 de março de 2020 como pandemia, já que estava presente em todos os continentes.

A disseminação do novo Coronavírus, o crescimento exponencial do número casos, inclusive com muitos casos de vítimas fatais ao redor do mundo, o receio do saturamento das estruturas hospitalares, impõe a necessidade do distanciamento social e, consequentemente, a suspensão do ensino presencial, como forma de preservarmos vidas humanas de estudantes, familiares e de todos os envolvidos, frente a esta pandemia, causada pela COVID-19.

\footnotetext{
A Organização Mundial da Saúde (OMS) declarou, em 30 de janeiro de 2020, que o surto da doença causada pelo novo coronavírus (COVID-19) constitui uma Emergência de Saúde Pública de Importância Internacional - o mais alto nível de alerta da Organização, conforme previsto no Regulamento Sanitário Internacional. Em 11 de março de 2020, a COVID-19 foi caracterizada pela OMS como uma pandemia. (PAMO - Organização Pan-Americana de Saúde, 2020)
}

As recomendações da OMS foram basicamente três: tratamento dos casos identificados, testes massivos nas populações e distanciamento social para evitar mais quantidade de pessoas 
contaminadas. Dessa forma, no Brasil, em 04 de fevereiro de 2020, o Ministério da Saúde publicou a Portaria no 188/GM/MS, declarando emergência em saúde pública de importância nacional, em razão da infecção humana pelo novo Coronavírus (COVID-19).

A publicação em nível nacional proporcionou em rede a criação de legislações próprias nos Estados e Municípios brasileiros, definindo normas para minimizar os impactos da pandemia, entre as quais a suspensão das atividades escolares, considerando o teor das Portarias n ${ }^{\circ}$ 343, 345 e 356 do Ministério da Educação, o que possibilitou a substituição das aulas presenciais na Educação Básica e Ensino Superior, por aulas em meios digitais, durante o período de pandemia de COVID19, sendo tal medida reafirmada pelo Conselho Nacional de Educação.

As publicações iniciais faziam a previsão de suspensão das aulas presenciais por 60 (sessenta) dias, porém, em virtude de a pandemia manter altos índices de crescimento de contaminações e óbitos no país, foram prorrogadas por legislações diversas em níveis nacionais e regionais, estendendo-se ao segundo semestre do ano letivo de 2020.

A suspensão das aulas presenciais, colocou em evidência duas situações presentes nas instituições brasileiras de diferentes níveis: a desigualdade social existente entre os educandos e as lacunas existentes no uso de Tecnologias de Comunicação e Informação - TIC para o ensino e a aprendizagem, tanto em recursos quanto na formação docente.

\section{Análise: Ensino Remoto à luz da Aprendizagem Significativa}

Durante o período de maio a julho/2020, foi realizada a pesquisa em uma escola pública que atende os Anos Iniciais do Ensino Fundamental em um município da Região Metropolitana da Baixada Santista. A escola encontra-se em local de difícil acesso e a maioria dos alunos atendidos se encontram em situação de vulnerabilidade social. A nova organização do processo educativo nesse novo formato remoto, mesmo sendo uma possibilidade para que os educandos não fiquem totalmente sem o direito à educação garantido, sabemos que:

É importante reiterar que a aprendizagem significativa se caracteriza pela interação entre conhecimentos prévios e conhecimentos novos, e que essa interação é não literal e não arbitrária. Nesse processo, os novos conhecimentos adquirem significado para o sujeito e os conhecimentos prévios adquirem novos significados ou maior estabilidade cognitiva. (MOREIRA, 2010, p. 2).

Dessa forma, a falta da interação e mediação pedagógica entre educador e educandos acaba sendo uma barreira, pois nesse novo desenho o professor tem mais dificuldades em compreensão acerca dos conhecimentos prévios que os alunos já possuem, considerando os a fragilidade nesse 


\section{Dialogia}

SOARES, Tárcila Lorrane Fernandes de Souza; SANTANA; Ícaro Silva de; COMPER, Maria Luiza Caires. Ensino remoto na pandemia de COVID-19: lições aprendidas em um projeto de extensão universitário

contexto dos subsunçores e dos princípios de inclusão obliteradora, considerados indispensável na teoria de Ausubel (2008).

Nesse contexto, os resultados demonstraram dificuldades como: conscientização das famílias sobre a importância do ensino remoto para minimizar os impactos causados pela suspensão das aulas presenciais, acesso aos recursos tecnológicos pelos alunos e formação dos docentes no uso das diferentes mídias no processo educativo, sendo as Tecnologias possibilidades para que os alunos compreendam melhor o mundo e as inter-relações existentes entre os diferentes seja no campo político, educacional, científico nos âmbitos global e local, tal como indica Silva (2002).

Os gestores da escola registraram os contatos com os alunos, assim como se desenvolveu processualmente a realização ou não das atividades propostas no ensino remoto no que tange à participação dos alunos. Pode-se demonstrar, conforme análise do gráfico da Figura 2:

Figura 2 - Participação dos Alunos na Escola Pesquisada

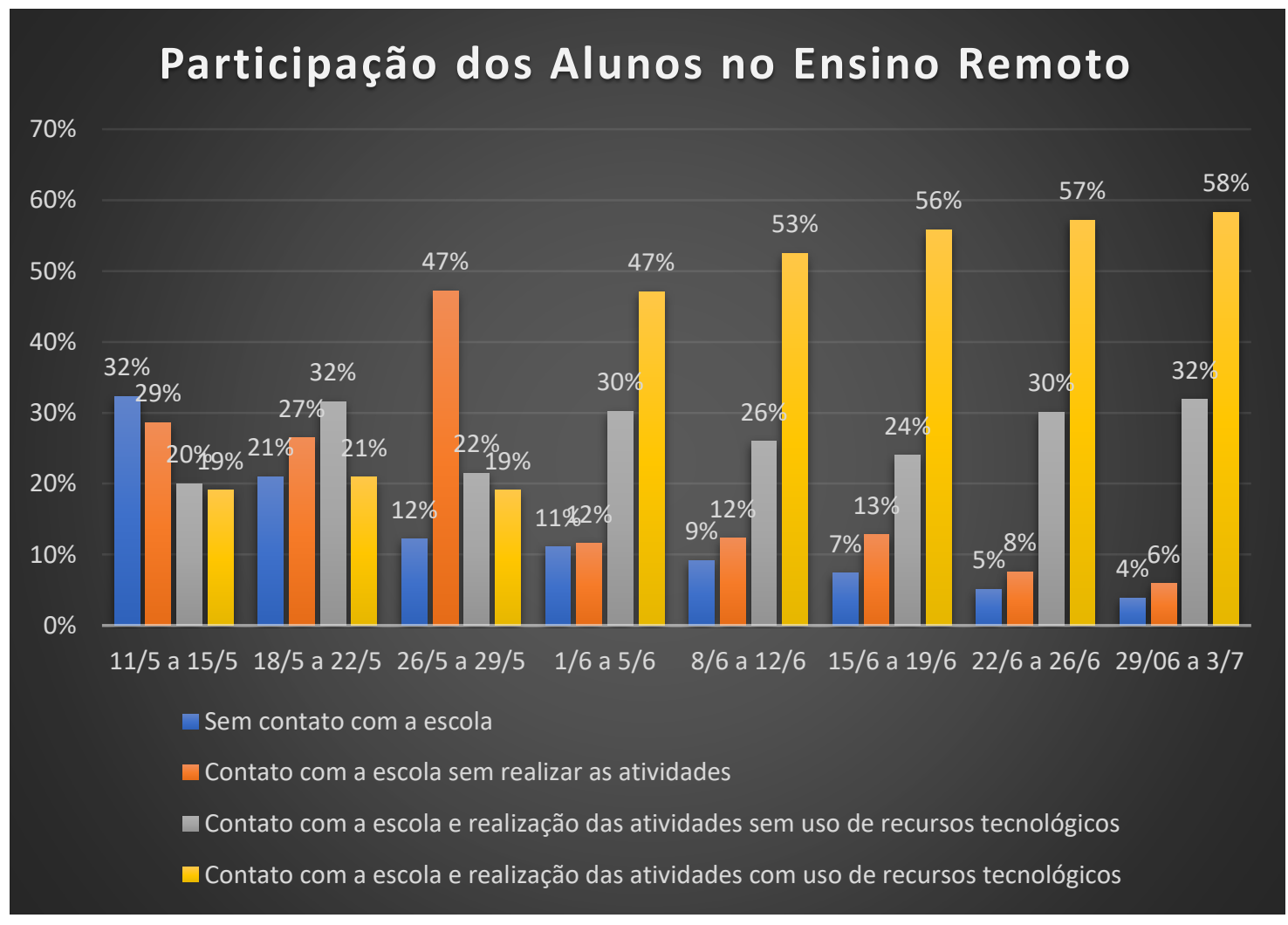

Fonte: Gestores de Ensino da Escola Pesquisada.

A Figura 2 possibilita compreendermos a dificuldade dos gestores da escola no contato com as famílias e com os alunos, o que foi atingido significativamente somente a partir da quarta semana. 


\section{Dialogia}

SOARES, Tárcila Lorrane Fernandes de Souza; SANTANA; Ícaro Silva de; COMPER, Maria Luiza Caires. Ensino remoto na pandemia de COVID-19: lições aprendidas em um projeto de extensão universitário

As atividades utilizadas por esses docentes durante o período remoto, buscaram considerar o contexto dos alunos, bem como os objetos do conhecimento nos aspectos epistemológicos e conceituais. As situações de aprendizagem foram preparadas para alunos que tivessem acesso aos recursos tecnológicos por meio de internet e adaptadas em folhas impressas aos alunos que não tinham tais recursos, com o objetivo de que esses alunos não fossem excluídos em virtude de suas condições socioeconômicas, situação já evidenciada antes da pandemia por Silva (2002).

A Figura 3 a seguir, mostra os recursos utilizados para os processos de ensino e de aprendizagem, segundo os professores que atuam nessa instituição pública de ensino:

Figura 3- Recursos tecnológicos utilizados pelos professores

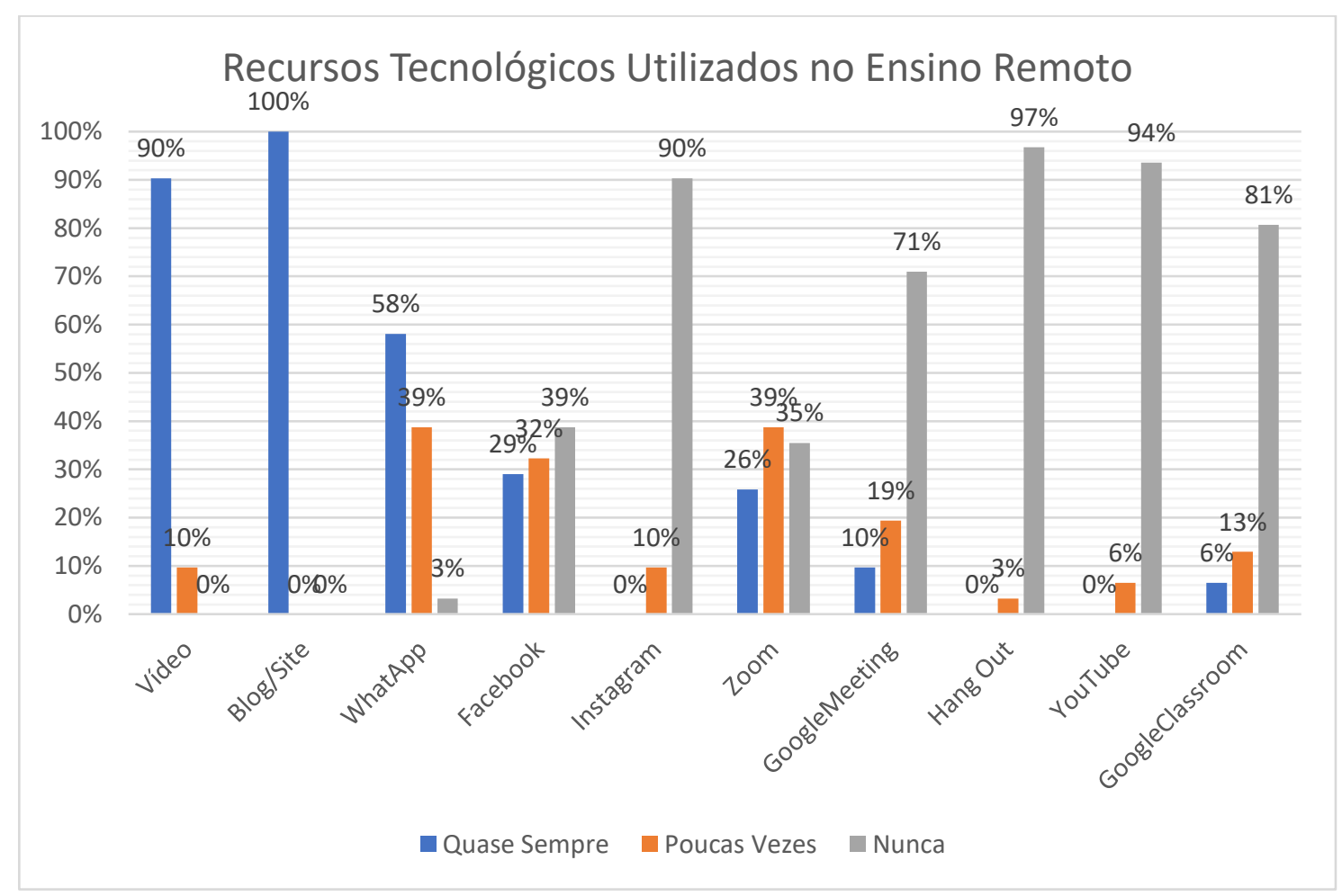

Fonte: Docentes de Ensino da Escola Pesquisada.

A Figura 3 nos indica que os meios mais utilizados foram os vídeos gravados e blog/site, onde os professores interagiam de forma assincrona, com os educandos, disponibilizando aula e atividades para que os alunos as realizassem para que, posteriormente, tivessem as correções e devolutivas pelos educadores.

Os princípios defendidos pela Base Nacional Comum Curricular (BRASIL, 2018) consideram a aprendizagem significativa, em que: 
Os conhecimentos prévios e as atribuições de sentido dependem das interações sociais. Nesse sentido, um tema é relevante para o estudante quando sua abordagem não é esvaziada de significado social, mas suas características socioculturais reais são mantidas. A escuta e circulação da palavra, durante a aula, é fundamental para identificação dos significados acerca do tema presentes entre os estudantes. (BRASIL, 2019).

Quanto às atividades criadas demonstraram grande comprometimento dos docentes com seus alunos, todos dessa instituição afirmaram que, pela primeira vez, estavam utilizando recursos tecnológicos para os alunos pudessem realizar atividades longe do ambiente escolar.

No tocante as ideias relacionadas à aprendizagem significativa, os professores demostraram preocupação com o contexto dos alunos e com a dificuldade das famílias em auxiliar nas atividades, mas foram identificadas lacunas no tocante aos aspectos epistemológicos e conceituais, indispensáveis à ancoragem dos alunos no desenvolvimento das competências que consideram os aspectos cognitivos aliados aos socioafetivos.

A análise de atividades propostas aos educandos possibilitou desvelar que algumas atividades propostas consideraram a aprendizagem significativa, mas com pouco desafio aos alunos, pois segundo os docentes, em virtude de não estarem presentes com os alunos, os mesmos apresentariam dificuldades na realização de atividades com maior grau de complexidadade. De qualquer forma, utilizaram alguns princípios da aprendizagem significativa e buscaram motivar os alunos, pois fazem referências a fatos presentes no período como a Festa Junina que iriam realizar, atividades de educação física, fazendo a conexão interdisciplinar com outras áreas do conhecimento.

Outro item interessante nesses problemas é a intersecção com diversas Unidades Temáticas, evidenciadas pela Base Nacional Comum Curricular - BNCC (BRASIL, 2017): Geometria, Grandezas e Medidas e Números.

Já em outras atividades, verificou-se que algumas pesquisas realizadas pelos alunos proporcionaram o desenvolvimento de competências acerca de informações da pandemia, além de reforçar o que a escola já vinha ensinando acerca das medidas de prevenção e higiene, bem como os sintomas mais frequentes nas pessoas contaminadas pelo novo corona vírus, destacando um trabalho fecundo com objetos do conhecimento e habilidades nesse novo cenário, vivenciado pelo isolamento, evidenciando a necessidade da reflexão por parte do professor acerca do que os alunos já sabem, tal como indica Ausubel (1963; 2003).

Assim, a investigação realizada pelos alunos demonstra a preocupação de os docentes no que tange à aprendizagem significativa, conforme Ausubel (2003) e Moreira (2012) ao considerar que a pesquisa fora realizada com um propósito de ampliar conhecimentos e transgredir as tarefas 
estritamente escolares para que atuem também como multiplicadores dos novos conhecimentos obtidos acerca da pandemia entre as pessoas da família que estão convivendo.

\section{Considerações finais}

Muitos estudos atuais têm indicado a importância da interação social e do senso de pertencimento como elementos-chave para a aprendizagem significativa, considerando os princípios ancorados na teoria de Ausubel (1963; 2008) e Moreira (1982; 2012).

Vale dizer que a prática docente ocorre no cotidiano escolar, influenciada por muitas variáveis, concretizando-se à medida que vai sendo construída. E assim, toda ação educativa visando a aprendizagem significativa requer constante reflexão antes, durante e depois de sua execução. Construir, desconstruir e reconstruir a ação.

O que se constatou é que a situação da pandemia e consequentemente a suspensão das aulas presenciais, evidenciou ainda mais as desigualdades sociais, já que os educandos que não possuíam recursos tecnológicos e acesso à internet tiveram as atividades adaptadas em folhas impressas em uma tentativa de minimizar que esses alunos não fossem excluídos em virtude de suas condições socioeconômicas.

Dialogar com uma aprendizagem significativa garante a oportunidade de oferecer um ambiente de aprendizagem humanizado e dialógico, mais próximo da realidade social do aluno, por meio do qual possam ter a possibilidade de compartilhar e construir seus conhecimentos. Considera-se que ao compartilhar o conhecimento por meio de uma construção dialógica é necessário ainda que essa aprendizagem seja, também, crítica.

Ao encontro dos princípios que a BNCC indica sobre a aprendizagem significativa, percebemos que apesar do contexto adverso os professores tentaram criar materiais que potencialmente fossem relevantes e significativos, sendo capazes de dialogar, de maneira apropriada com o conhecimento prévio dos estudantes (BRASIL, 2019).

Tendo como base os conhecimentos que traz consigo, experimentados no mundo, nas interações que vai fazendo, seja na diversidade do outro ou dos objetos de aprendizagem, nas metodologias diversificadas que reconhecem e respeitam habilidades, nos erros que permitem a retomada do caminho para uma ação mais assertiva e na compreensão do processo em si, efetivamente o sujeito, seja aluno ou professor, do processo de ensino e de aprendizagem aprende a pensar, a fazer perguntas e não esperar respostas.

O que se identificou na pesquisa realizada, apesar do interesse e comprometimento dos docentes, no período de isolamento social, foi uma formação com lacunas para o uso das 
SOARES, Tárcila Lorrane Fernandes de Souza; SANTANA; Ícaro Silva de; COMPER, Maria Luiza Caires. Ensino remoto na pandemia de COVID-19: lições aprendidas em um projeto de extensão universitário

Tecnologias de Informação e Comunicação, embora se tenha que registrar que os professores aprenderam sozinhos ou pela própria internet novas formas de desenvolver o processo educativo, construíram conhecimentos que ainda não tinham vivenciado em atividades escolares. $\mathrm{E}$ as crianças, aprenderam?

\section{Referências}

AUSUBEL, D. P. A Teoria da Aprendizagem Significativa segundo Ausubel. In: MASINI, E. F. S.; MOREIRA, M. A. Aprendizagem Significativa: condições de ocorrência e lacunas que levam a comprometimentos. 1ª ${ }^{\text {a }}$ ed. São Paulo: Vetor, 2008.

AUSUBEL, D. P. Aquisição e retenção de conhecimentos. Lisboa: Plátano Edições Técnicas, 2003.

AUSUBEL, D. P. The Psychology of Meaningful Verbal Learning. New York: Grune \& Stratton, 1963.

BRASIL. Ministério da Educação. Base Nacional Comum Curricular - $3^{\text {a }}$ Versão, 2017. Disponível em <http://basenacionalcomum.mec.gov.br>. Acesso em: 10. Jun. 2020.

BRASIL. Ministério da Educação. Base Nacional Comum Curricular. Aprendizagem Significativa - Breve discussão acerca do conceito. Disponível em: http://basenacionalcomum.mec.gov.br/implementacao/praticas/caderno-depraticas/aprofundamentos/191-aprendizagem-significativa-breve-discussao-acerca-do-conceito. Acesso em: 25 nov. 2020.

BRASIL. Ministério da Saúde. COVID 19. Disponível em:

https://coronavirus.saude.gov.br/sobre-a-doenca\#o-que-e-covid. Acesso em: 20. Jun. 2020.

CORTI, A. P.; VÓVIO, C. L. Jovens na alfabetização: para além de decifrar palavras, decifrar mundos. Brasília: Ministério da Educação / Ação Educativa, 2007.

FREIRE, Paulo. Educação e Mudança. Rio de Janeiro: Paz e Terra, 1976.

LABURÚ, C. Eduardo. Fundamentos para um experimento cativante. Caderno Brasileiro do Ensino de Física, v. 3, n. 3: p. 382-404, dez. 2006.

LA TAILLE, Y.; OLIVEIRA, M. K; DANTAS, H. Piaget, Vygotsky, Wallon: teorias psicogenéticas em discussão. São Paulo: Summus,1992.

MOREIRA, M. A. Mapas conceituais e aprendizagem significativa. São Paulo: Centauro Editora, 2006.

MOREIRA, M. A. O que é afinal aprendizagem significativa? Revista cultural La Laguna Espanha, 2012. Disponível em: http://moreira.if.ufrgs.br/oqueeafinal.pdf. Acesso em: 25 nov. 2020. 
MOREIRA, M. A. Uma abordagem cognitivista ao ensino da Física. Porto Alegre: Editora da Universidade, 1983.

MOREIRA, M. A.; MASINI, E. A. F. Aprendizagem significativa: a teoria de David Ausubel. São Paulo: Moraes, 1982.

PAMOS - Organização Pan Americana de Saúde. Boletim Folha Informativa - COVID 19 (doença causada pelo novo coronavírus). Disponível em:

https://www.paho.org/bra/index.php?option=com_content\&view=article\&id=6101:covid19\&I temid=875. Acesso em: 10 jul. 2020.

SACRISTAN, J. ; GÓMEZ, A.L. Pérez. Compreender e transformar o ensino. Porto Alegre: Artmed, 1998.

SAVIANI, Demerval. Escola e democracia: teorias da educação, curvatura da vara, onze teses sobre educação e política. São Paulo: Corte: Autores Associados, 1986.

SILVA, Marco. Sala de aula interativa. 2.ed. Rio de Janeiro: Quartet, 2002.

VYGOTSKY, Lev. A formação Social da Mente. São Paulo: Martins Fontes, 1984.

Recebido em: 26 jul. 2020 / Aprovado em: 01 dez. 2020

Cite como

(ABNT NBR 6023:2018)

CRUZ, Jucélia; TAVARES, Elizabeth dos Santos; COSTA, Michel da. Aprendizagem significativa no contexto do ensino remoto. Dialogia, São Paulo, n. 36, p. 411-427, set./dez. 2020. Disponível em: https://doi.org/10.5585/dialogia.n36.17760.

American Psychological Association (APA)

Cruz, J., Tavares, E. dos S., \& Costa, M. da. (2020, set./dez.). Aprendizagem significativa no contexto do ensino remoto Dialogia, São Paulo, 36, p. 411-427. https:// doi.org/10.5585/dialogia.n36.17760. 